\title{
Formulasi Dan Evaluasi Fisik Sediaan Gel Hand Sanitizer Minyak Atsiri Jeruk Kalamansi (Citrus macrocarpa Bunge)
}

\author{
Aina Fatkhil Haque ${ }^{a, 1 *}$, Betna Dewi ${ }^{a, 2}$, Lena Hartatia, 3 \\ a Program Studi D3 Farmasi, Sekolah Tinggi Kesehatan Al-Fatah, Kota Bengkulu, 38223 \\ 1ainafhaque@gmail.com; Betnadewi@gmail.com; ${ }^{3}$ lenahrtt66@gmail.com \\ *korespondensi penulis
}

\begin{tabular}{ll}
\hline INFO ARTIKEL & ABSTRAK \\
\hline Diterima : & Penelitian ini bertujuan untuk mengetahui kemampuan Minyak Atsiri Kulit \\
3I-I2-202I & Jeruk Kalamansi (Citrus microcarpa Bunge) untuk membuat sediaan gel hand \\
Direvisi : & sanitizer. Proses pembuatan sediaan gel hand sanitizer Minyak Atsiri Kulit Jeruk \\
03-0I-2022 & Kalamansi (Citrus microcarpa Bunge) menggunakan variasi konsentrasi Minyak \\
Disetujui : & Atsiri Kulit Jeruk Kalamansi (Citrus microcarpa Bunge) 0\%, I\%, 2\%, dan $4 \%$, \\
O3-OI-2022 & basis yang digunakan sebagai gelling agent yaitu carbomer, dan dilakukan \\
& evaluasi sediaan yang meliputi uji organoleptis, uji pH, uji viskositas, uji daya \\
& sebar, uji daya lekat, dan uji homogen. Hasil penelitian menunjukkan bahwa \\
Kata kunci: & Minyak Atsiri Kulit Jeruk Kalamansi (Citrus microcarpa Bunge) dapat dibuat \\
Jeruk Kalamansi; & sediaan gel hand sanitizer dan perbedaan konsentrasi dapat mempengaruhi sifat \\
Sediaan gel; & fisik sediaan gel hand sanitizer yang meliputi konsistensi dan bau gel hand \\
Handsanitizer; & sanitizer. Dari keempat formula F0 0\%, FI I\%, F2 2\%, dan F3 4\% sediaan \\
Minyak Atsiri; & yang paling baik adalah F3 dengan konsentrasi Minyak Atsiri Kulit Jeruk \\
Anti Bakteri. & Kalamansi (Citrus microcarpa Bunge) 4\% v/v
\end{tabular}

\section{Key word:}

Calamansi;

Gel;

Handsanitizer;

Essential Oil;

Antibacterial.

\section{ABSTRACT}

This review plans to decide the capacity of Kalamansi Orange Peel Essential Oil (Citrus microcarpa Bunge) to make hand sanitizer gel arrangements. The process of making hand sanitizer gel preparations of Kalamansi Orange Peel Essential Oil (Citrus microcarpa Bunge) using a concentration variety of Kalamansi Orange Peel Essential Oil (Citrus microcarpa Bunge) I\%, 2\%, 4\%, the base used as a gelling agent is carbomer, and an assessment was done. Arrangements which incorporate organoleptic test, $\mathrm{pH}$ test, Viscosity test, Dispersion test, adhesion test, and homogeneity test. The outcomes showed that Kalamansi Orange Peel Essential Oil (Citrus microcarpa Bunge) could be made into hand sanitizer gel arrangements and contrasts in focus could influence the actual properties of hand sanitizer gel arrangements which incorporated the consistency and scent of the hand sanitizer gel. Of the four equations F0 0\%, FI I \%, F2 2\%, dan F3 4\%, the best arrangement is F3 with a concentration of $4 \%$ v/v Kalamansi Orange Peel Essential Oil (Citrus microcarpa Bunge).

This is an open access article under the CC-BY-SA license.

\section{Pendahuluan}

Pemanfatan kekayaan alam di Indonesia dari dahulu sering digunakan, khususnya pada tumbuhtumbuhan yang telah dilakukan berbagai macam bentuk pembuatan seperti bumbu masak, bahan kerajinan dan obat tradisional. Sebagian besar tumbuhan berpotensi sebagai obat-obatan.
Berdasarkan literaturnya, kandungan utama yang terdapat dalam kulit jeruk kalamansi yaitu Minyak Atsiri dan pektin (Palma, 2019). Tanaman yang diketahui memiliki khasiat aktivitas antibakteri adalah tumbuhan kulit jeruk kalamansi (Citrus microcarpa Bunge) yaitu minyak atsiri. aktivitas antibakteri pada minyak atsiri disebabkan karena 
minyak atsiri mengandung senyawa yang dapat menghambat atau membunuh pertumbuhan bakteri (Pouvova, et al, 2008).

Minyak Atsiri Kulit Jeruk yang mempunyai komponen utamanya adalah limonen, mirsen dan decanal. Komponen mayor disebut juga dengan limonene.. Limonen diketahui memiliki aktivitas antimikroba dan antiseptik. Minyak Atsiri Kulit Jeruk Kalamansi (Citrus microcarpa Bunge) memiliki aktivitas sebagai Antibakteri terhadap bakteri Staphylococcus aureus dan Escherichia coli (Kamal., 20I I)

Limonene adalah hidrokarbon dalam siklus terpen yang berupa cairan, yang memiliki bau khas dari kulit jeruk. oleh sebab itu, diberi nama Limonen karena sebagian besar terdapat pada kulit jeruk. Limonen digunakan sebagai antibakteri yang dapat dibuat sediaan handsanitizer gel sebagai antiseptik dan antibakteri (Debora, dkk, 2018).

Berdasarkan penjelasan di atas, maka peneliti tertarik melakukan penelitian Minyak Atsiri Jeruk Kalamansi (Citrus microcarpa Bunge). Sebagai Formulasi Hand Sanitizer Gel. Diharapkan hasil dari penelitian ini dapat menjadi salah satu sediaan antiseptik yang bersumber dari bahan alam yaitu minyak atsiri

\section{Metode}

\section{Alat dan Bahan}

Bahan yang digunakan pada penelitian ini yaitu Minyak Atsiri Kulit Jeruk Kalamansi (Citrus microcarpa Bunge), alkohol 70\%, carbomer 940, TEA (trietanolamin), metil paraben, gliserin , dan aquadest.

Alat yang digunakan dalam penelitian ini adalah mortir dan stamper, beaker glass, penanggas air, timbangan gram dan milligram, gelas ukur, pengaduk kaca, kaca arloji, anak timbangan, objek glass, pipet tetes, $\mathrm{pH}$ meter, Viscometer Brookfield dan alat uji daya lekat.

Metode penelitian menguraikan tentang Tempat dan Waktu Penelitian, Alat dan Bahan Penelitian, Prosedur Penelitian dan Analisa Data

\section{Rancangan Formula}

Adapun formula Handsanitizer minyak kalamansi dibuat menjadi 3 formula, yaitu:

Tabel I. Formula Gel Hand sanitizer Minyak Atsiri

\begin{tabular}{ccccccc}
\multicolumn{7}{c}{ eruk Kalamansi } \\
\hline N & Bahan & F0 & FI & F2 & F3 & Khasiat \\
\hline I. & $\begin{array}{c}\text { Minyak } \\
\text { Atsiri }\end{array}$ & 0 & I & 2 & 4 & Zat Aktif \\
\hline 2. & $\begin{array}{c}\text { Alkohol } \\
70 \%\end{array}$ & 60 & 60 & 60 & 60 & Pelarut \\
\hline 3. & $\begin{array}{c}\text { Carbomer } \\
940\end{array}$ & 0,5 & 0,5 & 0,5 & 0,5 & Basis Gel \\
\hline
\end{tabular}

\begin{tabular}{ccccccc}
\hline 4. & TEA & 0,8 & 0,8 & 0,8 & 0,8 & $\begin{array}{c}\text { Zat } \\
\text { pengemul } \\
\text { si }\end{array}$ \\
\hline 5. & $\begin{array}{c}\text { Metil } \\
\text { Paraben }\end{array}$ & 0,2 & 0,2 & 0,2 & 0,2 & Pengawet \\
\hline 6. & Gliserin & I & I & I & I & pelembab \\
\hline 7. & $\begin{array}{c}\text { Aquadest } \\
\text { ad }\end{array}$ & I00 & I00 & I00 & I00 & Pelarut \\
\hline
\end{tabular}

\section{Cara Pembuatan}

Siapkan mortir dan stamper, lalu timbang carbomer 940. Setelah itu carbomer ditaburkan diatas aquadest. carbomer yang sudah ditaburkan lalu didiamkan selama 2 menit dan diaduk cepat dalam mortir sampai terbentuk masa gel dan ditambah TEA Lalu ditambah metil paraben. Diukur air mendidih, lalu larutkan metil parabennya, dan dimasukkan dalam mortir dan diaduk sampai ad homogen. Masukkan sisa alkohol, ditimbang minyak atsiri jeruk kalamansi sebanyak $1 \%, 2 \%$ dan 4\%..dimasukkan dalam mortir, dan dicampur sampai homogen. Dipindahkan kedalam beaker glass yang sudah dikalibrasi, ditambah aquadest sampai 100 $\mathrm{mL}$, diaduk ad homogen (Christian, 2016)

\section{Hasil Dan Pembahasan}

Minyak Atsiri Jeruk Kalamansi (Citrus microcarpa Bunge) meliputi uji organoleptis yang dimaksudkan untuk melihat tampilan fisik suatu sediaan yang meliputi warna, bau dan konsistensi secara kasat mata. Kemudian dilakukan uji $\mathrm{pH}$, uji viskositas, uji daya sebar, uji daya lekat dan uji homogenitas.

\section{Uji Organoleptis}

\begin{tabular}{ll}
\multicolumn{2}{c}{ Tabel 2. Hasil Uji Organoleptis } \\
\hline Organeleptis & Hasil \\
\hline Warna & Agak putih \\
\hline Bau & Khas minyak atsiri \\
\hline Konsistensi & Kental \\
\hline
\end{tabular}

Pada uji organoleptis dilakukan dengan cara mengamati menggunakan alat indra yang dilakukan secara kasat mata atau pengamatan secara langsung untuk mendeskripsikan dan mendapat kan hasil dari sediaan hand sanitizer gel minyak atsiri jeruk kalamansi (Citrus microcarpa Bunge) yang dimaksudkan untuk melihat tampilan fisik suatu sediaan yang mana bagian yang diamati meliputi warna, bau dan konsistensinya (Ulfah, dkk, 20I4). Hasil Uji organoleptis yang didapatkan yaitu berbentuk cairaan kental, berwarna agak putih dan berbau khas minyak atsiri kulit jeruk kalamansi (Citrus microcarpa Bunge). 


\section{Uji pH}

\begin{tabular}{ccccc}
\multicolumn{4}{c}{ Tabel 3. Hasil Uji $\mathrm{pH}$} \\
\cline { 2 - 4 } Formula & I & II & III & Rata-rata \\
& 5,00 & 6,08 & $7, \mathrm{I5}$ & 6,07 \\
\hline F0 & 5,15 & 6,23 & 7,26 & $6,2 \mathrm{I}$ \\
\hline FI & 5,28 & 6,35 & 7,38 & 6,34 \\
\hline F2 & 5,38 & 6,46 & 7,52 & 6,45 \\
\hline F3 & & &
\end{tabular}

Pengujian $\mathrm{pH}$ Sediaan gel hand sanitizer yang diaplikasikan dengan kulit harus memiliki $\mathrm{pH}$ yang sesuai yang telah ditentukan yaitu berkisar 6,8 7,2 . Nilai $\mathrm{pH}$ minyak atsiri kulit jeruk asam yaitu 5,22. Dalam hal ini, $\mathrm{pH}$ yang dimiliki kulit yaitu berkisar antara 4,5-6,5 (Draelos, et all, 20I2). Pengujian $\mathrm{pH}$ atau derajat keasaman digunakan untuk menyatakan tingkat keasaman atau kebasaan yang dimiliki oleh suatu sediaan. Semakin tinggi konsentrasi minyak atsiri jeruk kalmansi dan semakin lama penyimpanan maka semakin besar $\mathrm{pH}$ yang dihasilkan. Hasil dari uji $\mathrm{pH}$ hand sanitizer gel minyak atsiri kulit jeruk kalamansi (Citrus microcarpa Bunge) yang telah dilakukan semua formulasi memiliki rentang $\mathrm{pH}$ yang aman untuk kulit.

\section{Uji Viskositas}

Tabel 4. Hasil Uji Viskositas

\begin{tabular}{cccc}
\hline \multirow{2}{*}{ Formula } & \multicolumn{3}{c}{ Minggu ke } \\
\cline { 2 - 4 } & I & II & III \\
\hline F0 & 3.950 & 2.300 & 1.350 \\
\hline FI & 4.100 & 2.900 & 2.700 \\
\hline F2 & 5.100 & 3.400 & 3.000 \\
\hline F3 & 5.500 & 3.700 & 3.450 \\
\hline
\end{tabular}

Uji viskositas yang dilakukan agar pada saat kita mengaplikasikaan gel hand sanitizer dengan tangan terasa nyaman dikulit karena viskositas yang terlalu kental dapat menyebabkan sediaan sulit keluar dari wadahnya (Christian, 2016). Uji ini bertujuan untuk mengetahui konsistensi suatu sediaan yang berpengaruh pada penggunaan topikalnya. Hasil penelitian yang diperoleh menunjukkan bahwa semakin lama penyimpanan gel hand sanitizer dilakukan maka semakin encer sediaan yang didapatkan. Sediaan yang dihasilkan memenuhi spesifikasi yang diharapkan yaitu mudah dituang dan diteteskan pada telapak tangan. Selain itu, setelah sediaan diteteskan pada tangan maka akan segera larut pada suhu tubuh (Draeloz, 2012)

\section{Uji daya sebar}

Tabel 5. Hasil Uji Daya Sebar

\begin{tabular}{ccccc}
\hline Formula & \multicolumn{3}{c}{ Minggu ke } & Rata- \\
& I & II & III & rata \\
\hline
\end{tabular}

\begin{tabular}{ccccc}
\hline F0 & $\mathrm{I}, 2$ & $\mathrm{I}, 2$ & $\mathrm{I}, 3$ & $\mathrm{I}, 2$ \\
\hline FI & $\mathrm{I}, 2$ & $\mathrm{I}, 3$ & $\mathrm{I}, 3$ & $\mathrm{I}, 2$ \\
\hline F2 & $\mathrm{I}, 2$ & $\mathrm{I}, 3$ & $\mathrm{I}, 5$ & $\mathrm{I}, 3$ \\
\hline F3 & $\mathrm{I}, 4$ & $\mathrm{I}, 4$ & $\mathrm{I}, 5$ & $\mathrm{I}, 4$ \\
\hline
\end{tabular}

Uji daya sebar digunakan untuk dapat mengetahui kekentalan atau kelunakkan sediaan gel pada saat kita mengoleskan kekulit dan telapak tangan manusia, dan juga seberapa besar kemampuan gel untuk dapat menyebar sampai konstan atau tidak mengalami penyebaran lagi dengan penambahan beban (Naibaho, et all, 2013). Hasil penelitian yang didapat pada perbandingan FO, FI, F2, Dan F3 yaitu semakin tinggi kadar minyak atsiri jeruk kalamansi (Citrus microcarpa Bunge) maka daya sebar yang dihasilkan semakin besar. Hasil pengujian daya sebar menunjukkan sediaan yang memiliki daya sebar terbesar yaitu sediaan gel F3.

\section{Uji daya lekat}

\begin{tabular}{ccccc} 
& \multicolumn{3}{c}{ Tabel 6. Hasil Uji Daya Lekat } \\
\cline { 2 - 4 } Formulasi & \multicolumn{3}{c}{ Minggu ke } & Rata- \\
& I & II & III & rata \\
\hline F0 & 0I.26 & 0I.I4 & 0I.02 & 0I.I4 \\
\hline FI & 0I.37 & 0I.19 & 01.09 & 01.27 \\
\hline F2 & 0I.40 & 0I.34 & 0I.I4 & 0I.29 \\
\hline F3 & 0I.69 & 0I.56 & 0I.29 & 0I.5I \\
\hline
\end{tabular}

Uji daya lekat bertujuan untuk mengetahui berapa lama waktu pelekatan gel hand sanitizer minyak atsiri kulit jeruk kalamansi (Citrus microcarpa Bunge) pada permukaan kulit sehingga zat aktif dalam sediaan terabsorbsi (Nailufar, 2013). Syarat uji daya lekat untuk sediaan topikal adalah tidak lebih dari 4 detik (Ulaen, dkk, 20I2. uji daya lekat dengan F0 sampai F3 dari pengamatan yang dilakukan dari minggu ke I sampai minggu ke 3 uji daya lekat pada gel handsanitizer mengalami penurunan drastis, hal itu disebabkan karena lamanya penyimpanan pada suhu ruangan yang tidak stabil. hasil uji daya lekat dapat dilihat pada tabel 6 dan gambar grafik 6 diatas yang dilakukan pada FO, FI, F2, dan F3 semakin banyak Minyak Atsiri yang diberikan maka semakin turun daya lekatnya. Hasil pengamatan uji daya lekat yang telah dilakukan pada masing-masing formula diperoleh bahwa semakin tinggi konsentrasi minyak atsiri kulit jeruk kalamansi (Citrus microcarpa Bunge) yang diberikan maka semakin turun daya lekat yang didapat.

\section{Uji Homogenitas}

Tabel 3. Hasil Uji Homogen

\begin{tabular}{cccc}
\hline Formula & \multicolumn{3}{c}{ Minggu ke } \\
\cline { 2 - 4 } & I & II & III \\
\hline F0 & Homogen & Homogen & Homogen \\
\hline
\end{tabular}




\begin{tabular}{cccc}
\hline FI & Homogen & Homogen & Homogen \\
\hline F2 & Homogen & Homogen & Homogen \\
\hline F3 & Homogen & Homogen & Homogen \\
\hline
\end{tabular}

Pada pengujian ini adalah salah satu faktor yang sangat penting untuk dapat mengetahui bagaimana kualitas dari sediaan tersebut. Tujuan dilakukan pengujian homogenitas ini adalah untuk mengetahui, apakah komponen sediaan gel tersebut tercampur dengan baik dan tidak mengandung butiran-butiran atau partikel-partikel kasar yang belum terlarut pada sediaan tersebut (Ditjen, 2000). Hasil pengujian ini dapat dilihat bahwa diketahui pada semua formula dari F0, FI, F2, dan F3 yaitu memiliki sifat homongen yang sangat baik. Bahwa pada hal tersebut ditandai dengan hasil pengamatan yang dilakukan dengan mendapatkan hasil yang baik yaitu tidak mengandung atau tidak ada butiran kasar yang mengumpal pada sediaan atau partikel-partikel yang belum terlarut. Dalam sediaan gel terdispersi merata pada objek glass atau kaca transparan dan tidak ada pengumpalan partikel setelah diamati.

\section{Simpulan dan Saran}

Dari hasil penelitian yang telah dilakukan, maka dapat disimpulkan bahwa Minyak Atsiri Kulit Jeruk Kalamansi (Citrus microcapa Bunge) yaitu dapat diformulasikan dalam bentuk sediaan gel hand sanitizer dengan hasil evaluasi sediaan yang paling baik adalah F3 dengan konsentrasi 4\%

Berdasarkan penelitian yang dilakukan perlu adanya studi lanjutan dalam pengembangan bentuk sedian contohnya berupa nanopartikel.

\section{Ucapan Terimakasih}

Dalam kesempatan ini, penulis menyampaikan terima kasih yang sebesar-besarnya kepada Kementerian Riset Dan Teknologi, Republik Indonesia pada Skema Penelitian Dosen Pemula yang telah membiayai penelitian ini

\section{Daftar Pustaka}

C.E. Palma, P. S. Cruz, D. T. C. Cruz, A. M. S. Bugayong, and A.L.Castillo, (2019). "Chemical composition and cytotoxicity of philliphine calamansi essential oil, " Ind. Crops Prod., vol 128, no. October 20I8,pp. I08-II4.

Christian, E. (20I6). Optimasi Formula Sediaan Gel Hand sanitizer Minyak Atsiri Jeruk Bergamot Dengan Humektan Gliserin Dan Gelling Agent Carbopol, Skripsi.

Ditjen POM. (2000). Parameter Standar Umum Ekstrak Tumbuhan Obat Farmakope
Indonesia. Edisi IV. Jakarta : Departemen Kesehatan RI : 7-8

Ditjen POM. (2000). Parameter Standar Umum Ekstrak Tumbuhan Obat Farmakope Indonesia. Edisi IV. Jakarta : Departemen Kesehatan RI : 7-8

Draelos Z.D., (2012), Liquid Hand Cleanser and Sanitizer in Cosmetic Dermatology: Product \& Procedures, Blackwell Publishing Ltd., UK, Chapter I4, I06-I03.

G. Debora, K. Widya, A. Lolo, and P. V. Y. Yamlean. (2018). Uji Aktifasi Anti Bakteri Minyak Atsiri Kulit Buah Jeruk Kalamansi (Citrus microcarpa Bunge) Terhadap Bakteri Staphylococcus aureus dan Escherichia coli. J. Ilm. Farm., 7(4), pp. 6268.

Kamal, G. M., Anwar, F., Hussain, A. I., Sarri, N. , dan Ashraf, M. Y. (20II). Yield and chemical composition of Citrus essential oils as affected by drying pretreatment of peels. International Food Research Journal, I8(4): I275-I282.

Naibaho, O. H., Yamlean, P. V. Y., \& Wiyono, W., (2013), Pengaruh Basis Salep Terhadap Formulasi Sediaan Salep Ekstrak Daun Kemangi (Ocimum sanctum L.) Pada Kulit Punggung Kelinci Yang Dibuat Infeksi Staphylococcus aureus, Jurnal Ilmiah Farmasi, Vol. 2 No. 02.

Nailufar, N. P., Murrukmihadi M., dan Suprapto, (2013), Pengaruh Variasi Gelling Agent Carbomer 934 Dalam Sediaan Gel Ekstrak Etanolik Bunga Kembang Sepatu (Hibiscus rosa-sinensis L.) Terhadap Sifat Fisik Gel dan Aktivitas Antibakteri Staphylococcus Aureus, Skripsi, Fakultas Farmasi, Universitas Muhammadiyah Surakarta, Serakarta.

Pauvova, D., Kokoskova, B., and Pavela, R., (2008). Efektivity Of Plant Essential Oils Against Clavibacter Michiganensis, In Vitro. Zemdirbyste-Agriculture, 95(3): 440-446.

Puspitasari, F. (2009). Penetapan Kadar Kloramfenikol Dalam Tetes Mata Pada Sediaan Generik Dan Paten Secara Kromatografi Cair Kinerja Tinggi. Skripsi. Fakultas Farmasi : Universitas Muhammadiyah Purwokerto.

Ulaen, Selfie.P. J., Banne, Yos Suatan., and Ririn A. (2012). Pembuatan Salep Anti Jerawat Dari Ekstrak Rimpang Temulawak (Curcuma xanthorrhiza Roxb.). Jurnal Ilmiah Farmasi. 3(2): 45-49. 
Ulfa, M., Saifullah. S. T. N., dan Rima, M. (2014). Formulasi Sediaan Gel Antiseptik Tangan Minyak Atsiri Jeruk Lemon (Citrus limon (L) Burm. F) Dengan Basis Karbopol dan Aktivitas Antibakteri Terhadap Staphylococcus Aureus. Fakultas Farmasi. Skripsi. Universitas Muhammadiyah Surakarta. 